\title{
Estimating genetic parameters for fertility in dairy cows from in-line milk progesterone profiles
}

\author{
A. M. M. Tenghe, ${ }^{*} \dagger^{1}$ A. C. Bouwman, ${ }^{*}$ B. Berglund, $\ddagger$ E. Strandberg,, J. Y. Blom, $\S$ and R. F. Veerkamp ${ }^{*} \dagger$ \\ ${ }^{*}$ Animal Breeding and Genomics Centre, Wageningen UR Livestock Research, PO Box 338, 6700 AH Wageningen, the Netherlands \\ †Animal Breeding and Genomics Centre, Wageningen University, PO Box 338, $6700 \mathrm{AH}$ Wageningen, the Netherlands \\ †Department of Animal Breeding and Genetics, Swedish University of Agricultural Sciences, PO Box 7023, SE-750 07 Uppsala, Sweden \\ §Lattec I/S, Slangerupgade 69, DK 3400 Hillerød, Denmark
}

\section{ABSTRACT}

The aim of this study was to define endocrine fertility traits from in-line milk progesterone (P4) records and to estimate genetic parameters for these traits. Correlations of classical fertility (calving interval and calving to first service) and milk production traits with endocrine fertility traits were also estimated. In-line milk P4 records $(\mathrm{n}=160,952)$ collected from June 2009 through November 2013 for 2,273 lactations of 1,561 Holstein-Friesian cows in 12 commercial herds in the Netherlands were analyzed for (the log of) the number of days from calving till commencement of luteal activity (lnC-LA), proportion of samples between 25 and $60 \mathrm{~d}$ in milk with luteal activity (PLA), presence or absence of luteal activity for a cow between 25 and 60 $\mathrm{d}$ in milk, interval from commencement of luteal activity to first service (CLAFS), first luteal phase length, length of first interluteal interval, and length of first interovulatory interval. Milk P4 records were sampled, on average, every $2 \mathrm{~d}$. Genetic parameters were estimated using a mixed linear animal model. Heritability estimates $( \pm \mathrm{SE})$ of endocrine fertility traits were 0.12 \pm 0.05 for $\operatorname{lnC}$-LA, $0.12 \pm 0.05$ for PLA, and $0.11 \pm$ 0.06 for CLAFS, and their repeatability estimates were $0.29 \pm 0.04,0.21 \pm 0.04$, and $0.15 \pm 0.06$, respectively. The genetic correlation of $\operatorname{lnC}$-LA with PLA was -0.91 \pm 0.06 and with CLAFS was $-0.56 \pm 0.25$. The genetic correlations of $\operatorname{lnC}$-LA were $0.26 \pm 0.33$ with calving interval and $0.37 \pm 0.21$ with calving to first service. Genetic correlations of the milk production traits with $\operatorname{lnC}$-LA ranged from 0.04 to 0.18 and 0.07 to 0.65 with classical fertility traits. The phenotypic correlations of all endocrine fertility traits with milk production traits were close to zero (0.01 to 0.07$)$. This study shows that

Received August 11, 2014.

Accepted April 7, 2015.

${ }^{1}$ Corresponding author: amabel.tenghe@wur.nl in-line $\mathrm{P} 4$ records can be used to define and explore several heritable endocrine fertility traits in dairy cows and might help in selection for improved fertility.

Key words: dairy cow, fertility, in-line progesterone, heritability

\section{INTRODUCTION}

Fertility is an important component of herd production efficiency because each additional estrus cycle that does not result in a planned pregnancy adds to the cost of dairy farming. The negative effect of fertility on production efficiency is often reflected in increased number of inseminations per conception, higher involuntary herd replacement, high cost of veterinary intervention, and longer calving intervals. In addition to these negative effects, subfertility can affect the rate of genetic gain in other traits of economic importance.

Genetically improving fertility by selection with classical traits such as interval from calving to first service (CFS), calving interval (CInt), or days open is complicated by the low heritability of these traits (Jansen, 1985; Berry et al., 2003). These low heritabilities $\left(\mathrm{h}^{2}\right.$ $<0.1)$ may be explained by the fact that classical fertility traits are highly influenced by farm management decisions and poor recording practices (Hayes et al., 1992; Campos et al., 1994; Marti and Funk, 1994). For instance, a planned extended CInt will delay CFS not because a cow has a late start of cyclic activity, but because of the farmer's decision on when to inseminate, which results in large residual variance and low heritability estimates. Further indications that commercial farm management and recording might affect heritability estimates for classical fertility traits is the fact that larger heritability estimates $\left(h^{2}=0.13\right.$, for days open and CFS) have been estimated from records collected on an experimental farm under controlled management (Pryce et al., 1997). This low heritability of classical fertility traits makes it difficult to discriminate fertile genotypes at the cow level and, consequently, makes selection less effective. 
Endocrine fertility traits have been suggested as alternative indicators for fertility in dairy cows because they more directly reflect a cow's physiology (Bulman and Lamming, 1978; Lamming and Darwash, 1998; Darwash et al., 1999). For example, the interval from calving to first ovulation as determined by progesterone (P4) levels in milk could be used as a direct indicator of a cow's ability to return to luteal activity after calving, instead of an indirect indicator such as CFS. Several studies have revealed that endocrine fertility traits yield higher heritability estimates than classical fertility traits. Notably, for the interval from calving to commencement of luteal activity (C-LA), heritability estimates of 0.16 to 0.28 have been found, which is larger than for classical fertility traits (Darwash et al., 1997a; Veerkamp et al., 1998; Petersson et al., 2007). Furthermore, examination of phenotypic correlation of C-LA with classical fertility traits revealed that early reestablishment of cyclic activity in postpartum cows increases the probability of an early insemination after calving, shortens the interval from calving to conception, increases conception rate, and reduces the number of services per conception (Darwash et al., 1997b). These results further suggest that early reestablishment of cyclic activity is an important prerequisite for high fertility. In addition to C-LA, Darwash et al. (1997a) confirmed that milk P4 profiles could provide several objective heritable endocrine fertility traits. For example, corpus luteum competence and interluteal interval (ILI) were highly correlated with conception rate. Similarly, (Petersson et al., 2006) showed that endocrine fertility traits have moderate repeatability (0.14-0.16), suggesting more influence by the cow itself compared with classical fertility traits.

Although milk P4 levels have been widely accepted as valid indicators of fertility in dairy cows (Bulman and Lamming, 1978; Lamming and Darwash, 1998; Royal et al., 2002a), their application in routine genetic evaluation schemes has been constrained by the high cost associated with collecting these measures in sufficient number of samples per cow. Until recently, methods to measure milk P4 level were labor intensive. They often entailed manually taking several milk samples per cow, analyzing, and recording the results. However, P4 levelmeasuring technology has advanced to allow in-line systems to instantly measure milk P4 level (Friggens et al., 2008). In these systems, milk is automatically sampled, $\mathrm{P} 4$ level is measured, and results are recorded. Hence, more animals can be sampled at a lower cost, making it possible to have sufficient endocrine fertility traits for use in routine genetic evaluations. To use endocrine fertility traits from in-line milk P4 records in genetic improvement of fertility, the first step will be to examine whether these traits have sufficient genetic variation. Moreover, it will be important to know the correlation of in-line endocrine fertility traits with other traits included in the selection index before use in genetic improvement. To the best of our knowledge, no study has attempted to characterize heritable endocrine fertility traits in dairy cows from in-line milk $\mathrm{P} 4$ records. The aim of the current study was to define endocrine fertility traits from in-line milk progesterone records and estimate genetic parameters for these traits and their genetic correlations with classical fertility and milk production traits.

\section{MATERIALS AND METHODS}

\section{In-Line Milk Progesterone Records and Filtering Criteria}

Milk P4 records $(\mathrm{n}=226,188)$ collected from June 2009 through November 2013 were available for 2,514 Holstein-Friesian cows from 12 commercial dairy herds in the Netherlands. Milk sampling, measuring, and recording of P4 level was performed by the Herd Navigator (HN, DeLaval International, Tumba, Sweden). The HN is a management tool for dairy herds which samples and analyzes several milk constituents automatically during milking. One function of the HN is to monitor reproductive performance of cows by sampling and analyzing milk P4 level. This function is based on a bio-model that controls automatic in-line sampling, measuring, and recording of milk P4 level at varying intervals during a cow's estrus cycle (Friggens et al., 2008). Progesterone record files from each herd consisted of 4 variables: (1) herd number, (2) cow identification, (3) sampling date and time, and (4) sample value ( $\mathrm{P} 4$ level in $\mathrm{ng} / \mathrm{mL}$ ). These records were accompanied by corresponding data files with information on calving dates, parity, and data files with insemination dates. Linking of $\mathrm{P} 4$ records to calving data resulted in 3,648 lactations of 2,340 cows with 213,877 P4 records. In total, $5 \% \mathrm{P} 4$ records and $7 \%$ of cows were edited out after linking because their corresponding calving information was not available. Most cows were sampled from 27 to 176 DIM, with a mean sampling duration of 149 d. Milk P4 samples were taken on average every 2 d, with $25 \%$ of samples taken at an interval of less than $1 \mathrm{~d}$ and $75 \%$ at an interval of less than $4 \mathrm{~d}$.

Two sets of filtering criteria (FC) were applied to P4 records: herd-level FC and lactation-level FC. At the herd level, 2 criteria were applied. The management tool is recent and most herds installed the tool at a certain date when not all sampled cows were at the start of their lactation; therefore, a lactation was retained if 


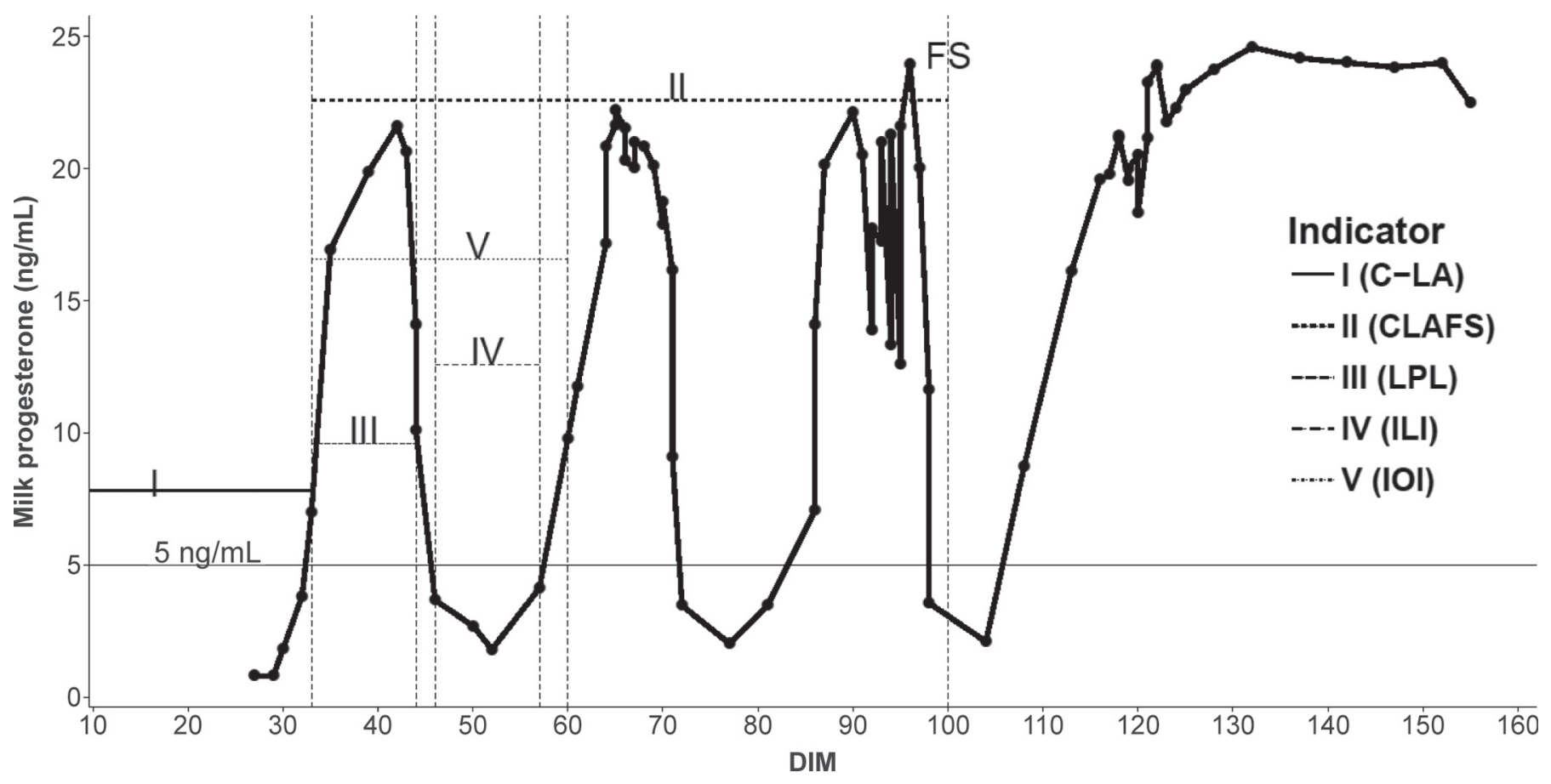

Figure 1. Milk progesterone level over DIM of a hypothetical dairy cow, used to define endocrine fertility traits. C-LA = interval from calving to commencement of luteal activity; CLAFS = interval from commencement of luteal activity to first service; LPL = first luteal phase length; ILI $=$ length of first interluteal interval (ILI); IOI = length of first interovulatory interval; FS = first service. The line at $5 \mathrm{ng} / \mathrm{mL}$ represents threshold for luteal activity; records above $5 \mathrm{ng} / \mathrm{mL}$ indicate occurrence of luteal activity, whereas records below $5 \mathrm{ng} / \mathrm{mL}$ indicate no luteal activity

the interval from calving to start of herd $\mathrm{P} 4$ recording was $\leq 25$ d. Similarly, because P 4 recording ended at different times in each herd, a lactation was retained if the interval from calving to end of herd $\mathrm{P} 4$ recording was $\geq 60 \mathrm{~d}$. At the lactation level, to reduce sampling variation due to differences in the start of $\mathrm{P} 4$ recording per lactation, 2 criteria were applied: (1) P4 samples taken before 25 DIM in a lactation were excluded, and (2) lactations for which $\mathrm{P} 4$ recording started after 35 DIM were excluded. After data filtering, 160,952 (75\%) $\mathrm{P} 4$ records of 2,353 (65\%) lactations for 1,630 (70\%) cows were retained. Data editing, filtering, and trait definition were carried out in R (R Core Team, 2013). The largest data loss was at herd level filtering. The number of $\mathrm{P} 4$ records, lactations, and cows retained after each filtering criterion are shown in Table 1.

\section{Defining Endocrine Fertility Traits}

For each lactation, the following endocrine fertility traits were defined (Figure 1).

$\boldsymbol{C}-\boldsymbol{L} \boldsymbol{A}$. Commencement of luteal activity refers to the interval from calving to start of luteal activity. A threshold of $5 \mathrm{ng} / \mathrm{mL}$ was used as indication for luteal activity. Commencement of luteal activity (indicator I, Figure 1) was defined as the number of days between day of calving and first day on which milk $\mathrm{P} 4$ level was elevated $(\geq 5 \mathrm{ng} / \mathrm{mL})$.

Commencement of Luteal Activity to First Service. Commencement of luteal activity to first service (CLAFS) refers to the interval from the initiation of luteal activity to first service (indicator II, Figure 1) and was measured from the first day of elevated P4

Table 1. Number of progesterone (P4) records, lactations (Lact), and cows retained by filtering criteria (FC)

\begin{tabular}{lcccccc}
\hline Criteria $^{1}$ & $\mathrm{P} 4$ & $\mathrm{P} 4(\%)$ & Lact & Lact $(\%)$ & Cows & Cows $(\%)$ \\
\hline Start data & 213,877 & 100 & 3,648 & 100 & 2,340 & 100 \\
Herd FC & 171,804 & 80 & 2,489 & 68 & 1,708 & 73 \\
Lactation FC & 160,952 & 75 & 2,353 & 65 & 1,630 & 70 \\
\hline
\end{tabular}

${ }^{1}$ Herd $\mathrm{FC}=$ exclude lactations with interval from calving to start of $\mathrm{P} 4$ recording $>25 \mathrm{~d}$ and lactations with interval from calving to end of $\mathrm{P} 4$ recording $<60 \mathrm{~d}$; Lactation $\mathrm{FC}=$ exclude $\mathrm{P} 4$ records taken before 25 DIM and lactations with start of P4 recording $>35$ DIM. 
level ( $\geq 5 \mathrm{ng} / \mathrm{mL}$ ), fitting the luteal activity criteria, to day of first service. This trait is not strictly endocrine, but a hybrid trait as it is defined from both $\mathrm{P} 4$ and insemination records.

First Luteal Phase Length. After ovulation, the period during which the corpus luteum secretes $\mathrm{P} 4$, measuring $\geq 5 \mathrm{ng} / \mathrm{mL}$, was referred to as the luteal phase (indicator III, Figure 1). The first luteal phase length (LPL) was defined as the interval from the first day of elevated $\mathrm{P} 4$ level $(\geq 5 \mathrm{ng} / \mathrm{mL})$ to the last consecutive day of elevated $\mathrm{P} 4$ level $(\geq 5 \mathrm{ng} / \mathrm{mL})$.

ILI. Interluteal interval refers to the period of anestrus between the demise of one corpus luteum and the rise of the next (indicator IV, Figure 1). Length of ILI was defined as the interval from the first day of decreased $\mathrm{P} 4$ level $(<5 \mathrm{ng} / \mathrm{mL})$ following the luteal phase, and the last consecutive day of decreased $\mathrm{P} 4$ level $(<5 \mathrm{ng} / \mathrm{mL})$.

Length of First Interovulatory Interval. Length of first interovulatory interval (IOI) refers to the interval between $\mathrm{P} 4$ level rise from the corpus luteum of 1 estrus cycle and the $\mathrm{P} 4$ level rise from corpus luteum of the next estrus cycle (indicator V, Figure 1). Length of IOI was defined from the first day of elevated $\mathrm{P} 4$ level $(\geq 5 \mathrm{ng} / \mathrm{mL})$ and the first day of elevated P4 level $(\geq 5$ $\mathrm{ng} / \mathrm{mL}$ ) following ILI.

Luteal Activity During the First 60 DIM. Luteal activity during the first 60 DIM (LA60) refers to the presence $(\mathrm{LA} 60=1)$ or absence $(\mathrm{LA} 60=0)$ of luteal activity between 25 and 60 DIM.

Proportion of Samples with Luteal Activity. Proportion of samples with luteal activity (PLA) refers to the number of $\mathrm{P} 4$ records with luteal activity ( $\mathrm{P} 4$ level $\geq 5 \mathrm{ng} / \mathrm{mL}$ ) divided by total number of $\mathrm{P} 4$ records in the period from 25 to 60 DIM. This trait gives an indication of the reproductive activity of a cow within 25 to 60 DIM, which could be quantified by alternative measures; for example, by taking the absolute number of $\mathrm{P} 4$ samples above a given maximum threshold of luteal activity. Although PLA could be affected by dynamic sampling, still taking the ratio of number of possible samples versus absolute numbers in luteal activity gives less bias in terms of bias that could be expected due to dynamic sampling.

In defining the endocrine fertility traits, a set of restrictions were applied to periods of nonsampling of $\mathrm{P} 4$ records that might occur during a lactation period. A period of no $\mathrm{P} 4$ sampling might be herd-specific and occur when the HN has a breakdown, resulting in gaps of no sampling. If these gaps are not taken into account, they can bias the defined endocrine traits. Recording gaps were identified at herd and at cow-lactation level. When cow lactations had no P4 samples for more than $7 \mathrm{~d}$, the following restrictions were applied: (1) if the gap occurred 1 or more days before C-LA (i.e., there was a low progesterone sample before CLA) and the gap duration was less than $15 \mathrm{~d}$ all traits were retained, otherwise all traits were excluded; and (2) if the gap occurred at least $25 \mathrm{~d}$ after C-LA all traits were retained, otherwise all traits were excluded except C-LA. Conversely, when the gap was herd-specific, all lactations on the given herd could be affected, hence when a gap was herd-specific the following restrictions were applied to all lactations on that herd. For each lactation, when a gap of 3 or more days occurred 1 or more days before C-LA all traits were retained. When a gap of 3 or more days occurred after C-LA, the following restrictions where applied: (1) LPL was retained if the gap occurred at least $25 \mathrm{~d}$ after C-LA; (2) ILI was retained if gap occurred 1 or more days before start of the interluteal interval; and (3) IOI was retained if gap occurred 1 or more days before start of the next luteal cycle. In total, 45 (2\%) lactations were affected by the restrictions applied to cow-lactation-specific gaps, and $144(6 \%)$ lactations for herd-specific gaps.

\section{Defining Classical Fertility Traits}

For all cows with defined endocrine fertility traits, extra lactation records for these cows were obtained from the national database to increase number of records. These records included the classical fertility traits CInt and CFS. The trait CInt was restricted between 300 and $700 \mathrm{~d}$, whereas CFS was restricted to 30 and 250 d. The following milk production traits were considered as well: accumulated milk yield (MY), protein yield (PY), and fat yield (FY) over 305 d of lactation. Of those, $55 \%$ of the lactations had their milk production traits from 305 DIM lactations, whereas $39 \%$ were predicted milk production traits over $305 \mathrm{~d}$ and $6 \%$ of lactations had no production traits. One herd did not participate in the national milk recording scheme, hence only records for fertility traits were used for that herd.

After trait definition, the data were linked to pedigree information. The pedigree $(\mathrm{n}=8,712)$ was traced back in the national database for each animal $(\mathrm{n}=1,561)$ with records. Pedigree data consisted of 514 paternal and 1,643 maternal half-sib groups. Maximum group size was 79 for paternal half-sibs and 4 for maternal half-sibs. Percentage of Holstein genes in cows were obtained from pedigree data. The final data used in genetic analysis consisted of 5,792 lactations of 2,119 cows. There were 2,273 lactations (80 lactations excluded due to no pedigree) of 1,561 cows with endocrine fertility traits, and 1,954 extra lactations with classical fertility 
and production traits from the national database for these cows. In addition, 1,565 lactations of 558 cows in the 12 herds with classical fertility and production traits but no endocrine traits were also included from the national database. Of the final data, 1,963, 1,525, 1,011 , and 1,293 lactations were in parity $1,2,3$, and $\geq 4$, respectively. The proportion of cows with repeated records per trait were: $33 \%$ for C-LA, $23 \%$ for CLAFS, $32 \%$ for PLA and LA60, $20 \%$ for LPL, $15 \%$ for ILI, $14 \%$ for IOI, $66 \%$ for CInt, $62 \%$ for CFS, and $74 \%$ for $\mathrm{MY}, \mathrm{PY}$, and FY.

\section{Genetic Analysis}

Data were analyzed with mixed linear models that use the restricted maximum likelihood method in ASREML (Gilmour et al., 2009). To estimate the heritability of each trait, variance components were obtained with a univariate animal model. The traits C-LA, LPL, ILI, and IOI were highly skewed, and thus were transformed (natural logarithm) to $\operatorname{lnC}$-LA, $\operatorname{lnLPL}, \operatorname{lnIILI}$, and lnIOI, respectively. Genetic and phenotypic correlations were obtained with bivariate models. The model used was:

$$
\begin{gathered}
\mathrm{y}_{\mathrm{ijklmn}}=\mu+\mathrm{p}_{\mathrm{i}}+\text { hys }_{\mathrm{j}}+\mathrm{b}_{1} \text { pch }_{\mathrm{k}}+\mathrm{b}_{2} \mathrm{ca}_{1} \\
+\mathrm{b}_{3} \mathrm{ca}_{1}^{2}\left(\mathrm{p}_{\mathrm{i}}\right)+\mathrm{a}_{\mathrm{m}}+\mathrm{pe}_{\mathrm{m}}+\mathrm{e}_{\mathrm{ijklmn}},
\end{gathered}
$$

where $y_{\mathrm{ijk} k m n}$ was the analyzed trait, $\mu$ was the intercept, $\mathrm{p}_{\mathrm{i}}$ was the fixed effect of parity i (cows in parity 4 or above were grouped to a common class); hys ${ }_{j}$ was the fixed effect of herd-year-season combination $\mathrm{j}$, with calving season defined as winter $=$ December to February, spring $=$ March to May, summer $=$ June to August, autumn $=$ September to November; $b_{1} p h_{k}$ was the fixed regression on percentage Holstein genes with coefficient $b_{1} ; b_{2} c_{1}$ was the fixed regression on age at calving 1 (in months) with coefficient $\mathrm{b}_{2} ; \mathrm{b}_{3} \mathrm{ca}_{1}{ }^{2}\left(\mathrm{p}_{\mathrm{i}}\right)$ was the fixed regression on age at calving 1 , fitted as a quadratic covariate, nested within parity $\mathrm{p}_{\mathrm{i}}$, with coefficient $\mathrm{b}_{3} ; \mathrm{a}_{\mathrm{m}}$ was the random genetic effect of cow $\mathrm{m}$ : $\sim N\left(0, \mathbf{A} \sigma_{a}^{2}\right), \mathbf{A}$ was the additive genetic relationship matrix and $\sigma_{a}^{2}$ was the genetic effects variance; $\mathrm{pe}_{\mathrm{m}}$ was the random permanent environmental effect of cow $\mathrm{m}$ to account for repeated measures within cow: $\sim N\left(0, \mathbf{I} \sigma_{\mathrm{pe}}^{2}\right), \mathbf{I}$ was an identity matrix including all animals (but animals without information on repeated records are automatically set at zero) and $\sigma_{\text {pe }}^{2}$ was the permanent environment variance; and $\mathrm{e}_{\mathrm{ijk} k \mathrm{mn}}$ was the random error term, $\sim N\left(0, \mathbf{I} \sigma_{e}^{2}\right)$, I was an identity matrix and $\sigma_{e}^{2}$ was the residual variance.
The same model was fitted for univariate and bivariate analysis. However, the number of repeated records was too low for the endocrine traits to estimate the correlation between traits for the permanent environmental effect and to separate this covariance from the genetic covariance between traits. Therefore, a reduced model was also fitted without this correlation included, and a data set was created without the repeated records per animal. The likelihood ratio test was used to test for the significant difference between the full bivariate model and the model without the permanent environmental covariance (the reduced model). From the likelihood ratio test, only 8 pairs of bivariate analysis (out of 33 ) gave a significant improvement for the full model. Still, some of the genetic correlations were affected and it is difficult to ascribe the covariance to a genetic effect if the data are not sufficient to disentangle genetic from permanent environmental effects. Therefore, the results of the full model will be presented in the results section and compared with the alternative model results in the discussion. Finally, the variance-covariance matrix was constrained to be positive definite. There was no large change in correlation estimates when the matrix was constrained. The absolute average change for correlations in the model without a constrained matrix and the model with a constrained matrix was 0.05 for correlations $\geq 0.75$ and 0.06 for other correlations.

\section{RESULTS}

Summary statistics for fertility and milk production traits are in Table 2. Overall, mean C-LA was 38.1 and mean CLAFS was 50.4 d. Minimum CLAFS was -46 , which occurs when a cow is inseminated before start of recorded luteal activity; $9(0.72 \%)$ records for CLAFS were negative. Days between CFS was $92 \mathrm{~d}$ on average and mean CInt was $410 \mathrm{~d}$, whereas average 305-d milk yield was $8,592 \mathrm{~kg}$ of milk. Mean LA60 was 0.88 , implying that $88 \%$ of cows were in luteal activity during the first 60 DIM, whereas mean PLA was $58 \%$. Large differences were observed at the herd level, as C-LA ranged from 32.4 to $45.3 \mathrm{~d}$ and milk yield from 7,070 to $10,140 \mathrm{~kg}$ of milk, whereas CLAFS ranged from 37.4 to $66.3 \mathrm{~d}$ across herds. Herd-average C-LA were also moderately correlated with longer calving intervals $(0.20)$, but strongly correlated with longer CFS (0.55).

Heritability estimates for the fertility traits reported in Table 3 ranged from 0.05 to 0.12 . The endocrine fertility traits $\operatorname{lnC}$-LA and PLA had moderate heritability $( \pm \mathrm{SE})$. Heritability of lnCL-A and PLA was $(0.12 \pm$ $0.05)$ with genetic standard deviations on the original scale $5 \mathrm{~d}$ and 0.10 , respectively, whereas heritability of CLAFS was $0.11 \pm 0.06$ with a genetic standard 
Table 2. Overall mean, standard deviation (SD), minimum (Min), maximum (Max), number of lactations (n), and skewness (Skew) for endocrine fertility traits, classical fertility traits, and milk production traits

\begin{tabular}{lccrrrr}
\hline Trait $^{1}$ & Mean & \multicolumn{1}{c}{ SD } & Min & Max & \multicolumn{1}{c}{$\mathrm{n}$} & Skew \\
\hline C-LA (d) & 38.1 & 17.8 & 25 & 187 & 2,165 & 2.42 \\
CLAFS (d) & 50.4 & 29.5 & -46 & 181 & 1,245 & 0.91 \\
LA60 (0-1) & 0.88 & 0.33 & 0 & 1 & 2,192 & -2.31 \\
PLA (\%) & 58 & 30 & 0 & 1 & 2,192 & -0.70 \\
LPL (d) & 13.0 & 11.5 & 2 & 106 & 1,055 & 3.77 \\
ILI (d) & 9.3 & 8.5 & 1 & 103 & 924 & 4.44 \\
IOI (d) & 26.2 & 13.3 & 5 & 115 & 932 & 2.54 \\
CInt (d) & 410 & 68 & 303 & 699 & 3,632 & 1.40 \\
CFS (d) & 92 & 36 & 30 & 250 & 4,413 & 1.36 \\
MY (kg) & 8,592 & 1,888 & 1,228 & 15,319 & 5,466 & 0.18 \\
PY (kg) & 301 & 63 & 43 & 532 & 5,466 & 0.13 \\
FY (kg) & 374 & 76 & 47 & 714 & 5,466 & 0.17 \\
\hline
\end{tabular}

${ }^{1} \mathrm{C}-\mathrm{LA}=$ Commencement of luteal activity; CLAFS = interval from commencement of luteal activity to first service; LA60 = luteal activity between 25 and 60 DIM; PLA $=$ proportion of samples in luteal activity between 25 and 60 DIM; LPL = first luteal phase length; ILI = length of first interluteal interval; , IOI = length of first interovulatory interval; CInt = calving interval; CFS = interval from calving to first service; $\mathrm{MY}=$ milk yield over $305 \mathrm{~d}$; PY = protein yield over $305 \mathrm{~d}$; FY = fat yield over $305 \mathrm{~d}$.

deviation of $9 \mathrm{~d}$. For the classical traits, heritability was $0.05 \pm 0.03$ for CInt and $0.11 \pm 0.03$ for CFS. Repeatability estimates of fertility traits ranged from 0.09 for CInt to 0.29 for $\operatorname{lnC}-\mathrm{LA}$, implying that a cow with an early C-LA has a low to moderate probability to have an early C-LA after the next calving. The traits lnILI, $\operatorname{lnLPL}$, and $\operatorname{lnIOI}$ had a close to or zero genetic variation (results not shown) and were therefore excluded from correlation analysis.

Correlations between fertility traits are in Table 4 . Due to low to moderate heritability and low number of records for some of the endocrine traits, standard errors for those genetic correlations were large. Therefore, the phenotypic correlations are discussed as proxies for the genetic correlations for those cases. There was a strong genetic correlation of $\operatorname{lnC}$-LA with PLA $(-0.91 \pm 0.06)$ and LA60 $(-0.86 \pm 0.03)$, and a longer lnC-LA (late start of luteal activity) was associated with shorter CLAFS $(-0.56 \pm 0.17)$.

All correlations of endocrine with classical fertility traits were in the direction that is expected from the trait definition. There was a moderate genetic correlation of CFS with $\operatorname{lnC}-\mathrm{LA}(0.37 \pm 0.21)$ and PLA $(-0.31 \pm 0.20)$, suggesting that cows with an early start of luteal activity and high reproductive activity have shorter intervals from calving to first service.

Correlations of milk production traits with all fertility traits are in Table 5. The genetic correlations of milk production traits with lnC-LA ranged from 0.04 to 0.18 and from 0.03 to 0.34 with other endocrine traits. With the exception of CLAFS, the phenotypic correlations of all endocrine traits with milk production traits were low (0.01 to 0.07) and, based on the standard errors (0.02 to 0.03$)$, not significantly different from

Table 3. Estimates of heritability, repeatability (t), and their SE for endocrine fertility traits, classical fertility traits and milk production traits, and number of lactations $(\mathrm{n})$ per trait $^{1}$

\begin{tabular}{|c|c|c|c|c|c|}
\hline Trait $^{2}$ & $\mathrm{n}$ & $h^{2}$ & $\mathrm{SE}$ & $\mathrm{t}$ & $\mathrm{SE}$ \\
\hline $\operatorname{lnC}-\mathrm{LA}[\ln (\mathrm{d})]$ & 2,165 & 0.12 & 0.05 & 0.29 & 0.04 \\
\hline $\operatorname{CLAFS}(\mathrm{d})$ & 1,245 & 0.11 & 0.06 & 0.15 & 0.06 \\
\hline LA60 (0-1) & 2,192 & 0.06 & 0.04 & 0.18 & 0.04 \\
\hline PLA $(\%)$ & 2,192 & 0.12 & 0.05 & 0.21 & 0.04 \\
\hline CInt (d) & 3,632 & 0.05 & 0.03 & 0.09 & 0.02 \\
\hline CFS (d) & 4,413 & 0.11 & 0.03 & 0.12 & 0.02 \\
\hline MY (kg) & 5,466 & 0.23 & 0.04 & 0.42 & 0.02 \\
\hline PY (kg) & 5,466 & 0.22 & 0.04 & 0.42 & 0.02 \\
\hline FY (kg) & 5,466 & 0.20 & 0.03 & 0.38 & 0.02 \\
\hline
\end{tabular}

${ }^{1}$ Heritability and repeatability estimates of $\operatorname{lnLPL}$, lnILI, and $\operatorname{lnIOI}$ are not shown, as they were close to or zero; $\operatorname{lnLPL}=$ natural logarithm of first luteal phase length; lnILI = natural logarithm of length of first interluteal interval; lnIOI = natural logarithm of length of first interovulatory interval.

${ }^{2} \operatorname{lnC}-\mathrm{LA}=$ natural logarithm of commencement of luteal activity; CLAFS = interval from commencement of luteal activity to first service; LA60 = luteal activity between 25 and 60 DIM; PLA $=$ proportion of samples in luteal activity between 25 and 60 DIM; CInt = calving interval; CFS = interval from calving to first service; $\mathrm{MY}=$ milk yield over $305 \mathrm{~d}$; PY $=$ protein yield over $305 \mathrm{~d} ; \mathrm{FY}=$ fat yield over $305 \mathrm{~d}$. 
Table 4. Estimates of genetic (below diagonal) and phenotypic (above diagonal) correlations, of endocrine and classical fertility traits with SE in parentheses

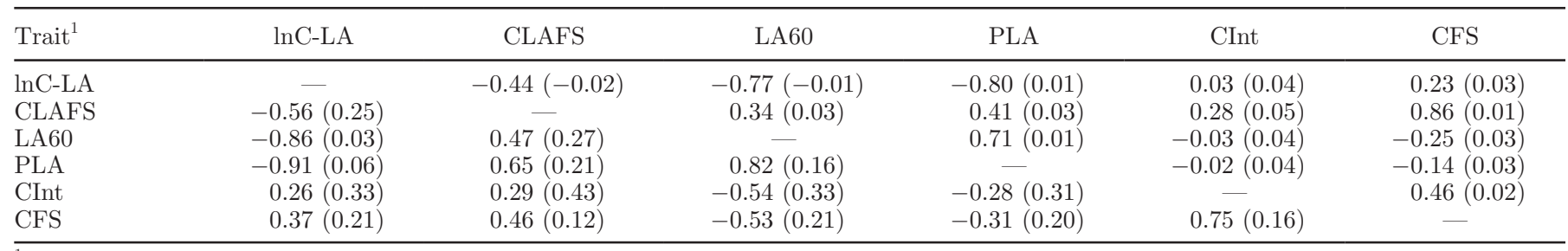

${ }^{1} \operatorname{lnC}-\mathrm{LA}=$ natural logarithm of commencement of luteal activity; CLAFS = interval from commencement of luteal activity to first service; LA60 $=$ luteal activity between 25 and 60 DIM; PLA = proportion of samples in luteal activity between 25 and 60 DIM; CInt = calving interval; CFS $=$ interval from calving to first service.

zero. For phenotypic correlations of CLAFS with milk production traits, estimates of up to $0.14 \pm 0.03$ were obtained.

\section{DISCUSSION}

The uniqueness of our study is that in-line milk $\mathrm{P} 4$ records were used to characterize endocrine fertility traits. As a consequence, $\mathrm{P} 4$ level sampling frequency was higher, and more $\mathrm{P} 4$ records were available per lactation than in previous studies. Moreover, previous studies on characterization of heritable endocrine fertility traits have been based on manually collected milk samples for $\mathrm{P} 4$ recording, which is not practical for breeding programs, mainly because routine milk recording samples are taken only every 4 to 6 wk. In our study, genetic variation of similar size, as in previous studies, were found for some of the endocrine fertility traits. Heritability estimates were greatest for $\operatorname{lnC}$-LA and PLA $(0.12 \pm 0.05)$ and CLAFS $(0.11 \pm 0.06)$, and lnC-LA was strongly correlated with PLA $(-0.91 \pm$
0.06). Correlations of classical fertility traits (CInt and CFS) and milk production traits (MY, PY, and FY) with endocrine fertility traits were also examined. All correlations of endocrine traits with classical fertility traits were as expected, and there was a near-zero phenotypic correlation of endocrine fertility traits with yield traits.

\section{Characterization of Endocrine Fertility Traits}

The overall mean for C-LA (38.1 d) can be used as an indication of the interval from calving to first ovulation, which occurs on average $5 \mathrm{~d}$ before C-LA (Bulman and Lamming, 1978); hence, on average, ovulation would have occurred in our study on approximately d 33 postpartum. The mean C-LA in our study was $8.6 \mathrm{~d}$ longer than the estimate $(29.5 \mathrm{~d}$ ) reported by Veerkamp et al. (2000) for Dutch cows. Petersson et al. (2006) reported a mean C-LA of $33.8 \mathrm{~d}$ for data collected in the period of 1987 to 2002 on Swedish Holstein-Friesian and Swedish Red and White cows, whereas using data collected

Table 5. Genetic and phenotypic correlations between fertility traits (endocrine and classical) and milk production traits with SE in parentheses ${ }^{1}$

\begin{tabular}{|c|c|c|c|c|c|c|}
\hline Trait $^{2}$ & \multicolumn{3}{|c|}{ Phenotypic } & \multicolumn{3}{|c|}{ Genetic } \\
\hline $\operatorname{lnCLA}$ & $0.03(0.03)$ & $-0.02(0.03)$ & $0.01(0.03)$ & $0.18(0.20)$ & $-0.04(0.20)$ & $-0.12(0.21)$ \\
\hline CLAFS & $0.13(0.03)$ & $0.14(0.03)$ & $0.13(0.03)$ & $0(0.25)$ & $0.04(0.25)$ & $0.42(0.15)$ \\
\hline LA60 & $0.02(0.02)$ & $0.07(0.02)$ & $0.05(0.02)$ & $-0.34(0.25)$ & $-0.21(0.25)$ & $0.12(0.26)$ \\
\hline CInt & $0.21(0.02)$ & $0.21(0.02)$ & $0.21(0.02)$ & $0.56(0.23)$ & $0.69(0.25)$ & $0.65(0.24)$ \\
\hline CFS & $0.15(0.02)$ & $0.13(0.02)$ & $0.14(0.02)$ & $0.14(0.15)$ & $0.07(0.16)$ & $0.24(0.16)$ \\
\hline
\end{tabular}


from 2003 through 2005 on British cows, Pollott and Coffey (2008) observed mean C-LA of 32.4 d. Furthermore, Royal et al. (2000) found a shorter C-LA, 27.9 d, for data collected from 1995 to 1998 in British cows. In addition, C-LA as low as $24.7 \mathrm{~d}$ for data collected from 1976 to 1977 has been reported (Bulman and Lamming, 1978). One likely reason for the mean difference of C-LA between these studies is differences in data recording and editing. For example, in our study most herds did not start recording P4 before 25 DIM, hence this was used as the lower boundary for the data, whereas in most of the previous studies $\mathrm{P} 4$ recording started earlier after calving. However, the mean difference might also be the result of population differences or declining fertility in dairy cattle (Lucy, 2001; Pollott and Coffey, 2008).

Proportion of samples in luteal activity (PLA) might be an informative indicator for dairy cow fertility. In addition to C-LA, PLA not only measures start of luteal activity, but also gives an indication of a cow's cyclicity after first ovulation. Because PLA was quantified based on P4 records between 25 and 60 DIM, it gives an indication of the reproductive activity of a cow postpartum for this period of time, but the period can be easily extended and could be useful for management purposes. Another advantage of PLA is that it can be quantified for more animals than C-LA at a given time after calving. Animals without a C-LA in the first 60 $\mathrm{d}$ have a missing C-LA, but will have a score for PLA. In our study, more lactations with $\mathrm{P} 4$ records received a measure for PLA $(\mathrm{n}=2,192)$ than for C-LA $(2,165)$, but PLA may have the disadvantage that it is affected by the number of samples taken in a fixed period. Because $\mathrm{P} 4$ records were sampled on average every $2 \mathrm{~d}$, mean PLA (58\%) was higher than the values of 37 and $47 \%$ that have been reported elsewhere (Petersson et al., 2006; 2007), where P4 records were sampled 1 to 3 times per week. Furthermore, a decrease in mean PLA was also observed when P4 sampling frequency was decreased from twice weekly to twice monthly (Petersson et al., 2007). Another disadvantage of PLA is that very high values could be associated with poor reproductive performance (e.g., persistent corpus luteum or pyometra; Etherington et al., 1991; Petersson et al., 2007). The occurrence of luteal activity during the first 60 DIM (LA60) is a new trait that has the same advantages as PLA, but LA60 has the disadvantage of being a binary trait.

Repeatability estimates for endocrine fertility traits (0.15 to 0.29 ) were generally moderate, whereas those for classical fertility traits were low (0.09 to 0.12). This supports the hypothesis that endocrine measures of fertility are more influenced by the cow itself and better reflect the cow's own physiology than classical fertility measures, which are biased by farm management decisions and recording practices. The repeatability for lnC-LA was similar to that of Darwash et al. (1997a). Moreover, a moderate repeatability for lnC-LA (0.29) suggests that cows with shorter intervals from calving to first ovulation have the tendency to have such short intervals after every calving.

\section{Genetic Parameters}

Heritability estimates for endocrine fertility traits varied from 0.06 to 0.12 . The heritability of $\operatorname{lnC}-\mathrm{LA}$ $(0.12 \pm 0.05)$ was at the lower bound of previously reported estimates (0.13 to 0.21; Darwash et al., 1997a; Veerkamp et al., 2000; Berry et al., 2012). However, the genetic standard deviation of lnC-LA (0.12) in our study, which is equivalent to approximately $5 \mathrm{~d}$, implies that considerable genetic variation exists in $\operatorname{lnC}$-LA. Most previous studies defined C-LA and other endocrine traits using $3 \mathrm{ng} / \mathrm{mL}$ as a threshold for luteal activity, whereas our study used $5 \mathrm{ng} / \mathrm{mL}$. To investigate the effect of the threshold on the heritability of $\operatorname{lnC}-\mathrm{LA}$, the analysis with $3 \mathrm{ng} / \mathrm{mL}$ was also performed, but that did not affect the heritability of lnC-LA. Phenotypic variation in CLAFS has been studied (Royal et al., 2000), but no other estimates are available for the genetic variation. The genetic standard deviation for CLAFS was $9 \mathrm{~d}$, so considerable genetic variation was also observed for this trait. Heritability of PLA (0.12 $\pm 0.05)$ was lower than the estimate $(0.29 \pm 0.06)$ of Petersson et al. (2007). However, the genetic standard deviation for PLA (0.10) implies that considerable genetic variation also exists for this trait. The heritability of CInt in our study was in agreement with previous studies (Wall et al., 2003; Berry et al., 2012), but the heritability of CFS was slightly larger than generally observed from field data.

Besides possible reasons such as sample size, population structure, and other factors that might influence heritability estimates, one possible reason for the lower estimates of endocrine fertility traits in our study compared with previous reports might be the data-editing steps applied. By excluding all lactations for cows not sampled before 25 DIM or for at least 60 DIM, a sampling bias might have been introduced and resulted in biased estimates for endocrine fertility traits. However, the considerable genetic variation and moderate repeatability estimates of the endocrine fertility traits found in our study led to the conclusion that no important bias existed and substantial genetic improvement can be achieved if the accuracy of identifying genetically superior animals is high. 
The correlations of $\operatorname{lnC}$-LA with PLA $(-0.91 \pm 0.06)$ and CLAFS $(-0.56 \pm 0.17)$ implies that direct selection for shorter lnC-LA will lead to increased reproductive activity, but also to increased CLAFS. The strong correlation of PLA with lnC-LA means that PLA could be used for selection in cases where C-LA cannot be quantified for all animals, though some checks for reproductive abnormalities should be considered, as very high values of PLA are sometimes associated with persistent corpus luteum or pyometra. Comparable correlations between $\operatorname{lnC}-\mathrm{LA}$ and PLA $(-0.97 \pm 0.05)$ have been reported (Petersson et al., 2007). Also, moderate genetic correlation $(-0.31 \pm 0.20)$ was noted between PLA and CFS, whereas Petersson et al. (2007) found a low estimate $(-0.03 \pm 0.22)$ but of same sign and both with large standard errors. The genetic correlation of $\operatorname{lnC}$-LA with CFS $(0.37 \pm 0.21)$ and CInt $(0.26 \pm 0.33)$ imply that decreasing $\operatorname{lnC}$-LA by 1 genetic standard deviation will decrease CFS by $4.1 \mathrm{~d}$ and CInt by $3.7 \mathrm{~d}$. Some studies have examined the correlations between endocrine and classical fertility traits. Nyman et al. (2014) found a correlation of $0.54 \pm 0.27$ between $\operatorname{lnC}$ LA and CInt. Fitting a genetic regression of daughter lnC-LA on sire PTA for CInt, Royal et al. (2002b) inferred a genetic correlation of 0.36 between $\operatorname{lnC}-\mathrm{LA}$ and CInt, whereas Berry et al. (2012) reported an estimate of $0.87 \pm 0.33$ from an animal model. Similarly, positive genetic correlations between lnC-LA and CFS $(0.37 \pm$ 0.34 and $0.35 \pm 0.12$ ) have been reported (Berry et al., 2012; Nyman et al., 2014).

The results discussed thus far were estimated including the correlation between permanent environmental effects across traits (full model). As too few (repeated) records were available to estimate both the genetic and permanent environmental correlation between traits very accurately, 2 alternative analyses were performed to investigate the effect on the estimated genetic correlations. First, a reduced model was fitted that excluded the permanent environmental correlation between traits (but included the permanent effect for each trait); second, an analysis without repeated records was performed. Comparing the likelihood from the reduced and full model, the permanent environmental covariance between traits could have been excluded for 25 (out of 33) of the analyses. However, excluding the permanent environmental covariance or not had an effect on some of the genetic correlation estimates, especially for CLAFS; its genetic correlations with milk production traits from the full model were $0.00 \pm 0.25$ for $\mathrm{MY}, 0.04 \pm 0.25$ for $\mathrm{PY}$, and $0.42 \pm 0.15$ for $\mathrm{FY}$, but moved to $0.40 \pm 0.17$ for MY, $0.45 \pm 0.17$ for PY, and $0.53 \pm 0.19$ for FY with the reduced model. Hence, the 2 models seemed to be conflicting, either suggesting no genetic correlation (full model) between CLAFS and MY or a moderate genetic correlation (reduced model). This illustrates the confounding between the permanent and genetic correlation. The analysis where all repeated records were deleted and genetic correlations reestimated gave low genetic correlations of CLAFS with MY $(0.09 \pm 0.31)$, but $0.24 \pm 0.32$ for PY and $0.70 \pm 0.44$ for FY. However, the genetic correlations of the different models were not statistically significantly different from each other, and therefore there is still an open question of whether a positive genetic correlation exists between CLAFS and MY or not. However, it is clear that properly accounting for a permanent environmental effect for each cow, which is likely to be influenced by voluntary waiting period determined by the farmer when a cow is inseminated or not, and having enough (repeated) records to separate theses effects is important when concluding on the association between yield and fertility traits.

The positive genetic correlation between $\operatorname{lnC}-\mathrm{LA}$ and milk production traits suggests an unfavorable influence of genetic merit for milk yield on genetic merit for lnC-LA, but this correlation was considerably lower than estimates reported in previous studies. Veerkamp et al. (2000) reported higher correlations of C-LA with MY (0.51), PY (0.48), and FY (0.65) for 305-d yield records, whereas Royal et al. (2002a) found an estimate (0.36) for lnC-LA with predicted milk yield on d 56 and Nyman et al. (2014) found a genetic correlation of 0.45 \pm 0.09 for lnC-LA with ECM during the first 60 DIM. Furthermore, the negative genetic correlations between PLA and milk production traits suggest an unfavorable influence of genetic merit for yield on genetic merit for PLA. No previous study has reported correlations for PLA and milk production traits. Nonetheless, the correlations of endocrine fertility traits and milk production traits in our study are considerably lower than has been observed between classical fertility and milk production traits (Pryce et al., 1997; 1998). The results from our study support and expand the work of Darwash et al. (1997a), Royal et al. (2002b), and Petersson et al. (2007), that endocrine fertility traits might serve as better indicators of dairy cow fertility. In addition, Berry et al. (2012) were able to identify 2 markers on the genome associated with C-LA that have not been identified with classical fertility traits, suggesting that endocrine fertility traits might be more useful for mapping genomic regions and studying the biology of fertility. Moreover, endocrine fertility traits can also help provide valuable insights to the consequences of selection for different aspects of fertility, or, conversely, be very useful in understanding how selection for other traits effects on fertility in great detail. 


\section{Application of Endocrine Fertility Traits in Breeding Schemes}

The breeding goal trait for fertility would be cows that resume luteal activity early after calving, start showing heat so they can be inseminated at the optimal time point, are pregnant after first insemination, and calve successfully. None of these traits are measured on a sufficient large scale to select on these traits directly. The use of endocrine fertility traits might provide a better trait definition, with the added advantage that they provide an elaborate definition of the breeding goal. However the use of endocrine fertility traits has been limited by the costs associated with frequent sampling of $\mathrm{P} 4$ records per cow and on a large number of animals required for genetic evaluation. Alternatives, such as sampling of daughters of bulls only during normal milk recording (van der Lende et al., 2004) or sampling at the cow level on a monthly basis (Petersson et al., 2007), have been suggested. In-line P4 records may provide a new opportunity to address these limitations.

Our study has provided several endocrine fertility traits with genetic variation that might serve as breeding goal traits. For example, in breeding programs where CFS is used as index trait as indirect measure of calving to first ovulation, lnC-LA is likely to be a more direct measure of return to reproductive cyclicity, as there is only a delay of 4 to $5 \mathrm{~d}$ between C-LA and first ovulation. Hence, in accordance with Petersson et al. (2007), we suggest using $\operatorname{lnC}$-LA as a trait in the breeding goal rather than CFS. Also, CLAFS might provide a measure for heat and heat detection although it is partly affected by insemination decision, and PLA might be an interesting trait to be considered as indicating reproductive abnormalities because most of the detailed traits such as LPL, ILI, and IOI gave zero heritability in our study. Nonetheless, classical fertility traits are measured on a large scale and might still serve as predictor traits in the national genetic evaluations. Thus, endocrine fertility traits provide the option of a more precise definition of the breeding goal.

Also to be considered is the fact that few herds possess the in-line recording system, although the number of herds with this system is increasing and in the near future it might be possible to use endocrine fertility traits in genetic evaluation schemes. However, because of the few herds, in-line endocrine fertility traits would be most useful in a genomic selection scheme, where cows from collaborator herds would be part of the reference population and for the national breeding schemes genomic prediction are used for endocrine fertility traits. Therefore, combining (genomic predictions for) endocrine and classical fertility traits may provide the most accurate information for the selection of a more precise definition of dairy cattle breeding goals based on endocrine fertility traits.

\section{CONCLUSIONS}

We showed that in-line $\mathrm{P} 4$ records can be used to define and explore several endocrine fertility traits in dairy cows. Some of these traits have genetic variation and might help to define better breeding goals to select for improved fertility. Nonetheless, because few herds use the in-line recording system, endocrine fertility traits would only be more useful in a genomic selection scheme.

\section{ACKNOWLEDGMENTS}

The authors acknowledge Lattec I/S for providing the in-line progesterone data and the Cooperative Cattle Improvement Organization CRV BV (Arnhem, the Netherlands) for providing the pedigree data for this study. A. M. M. Tenghe benefited from a joint grant from the European Commission and the European Union Seventh Research Framework Programme (FP7/ 2007-2013) under the grant agreement n³11776, within the framework of the Erasmus-Mundus joint doctorate "EGS-ABG" (Paris, France). This study was also performed as part of the Prolific project. The Prolific project is financially supported by the European Commission under the Seventh Research Framework Programme, Grant Agreement n³11776.

\section{REFERENCES}

Berry, D. P., F. Buckley, P. Dillon, R. D. Evans, M. Rath, and R. F. Veerkamp. 2003. Genetic relationships among body condition score, body weight, milk yield, and fertility in dairy cows. J. Dairy Sci. 86:2193-2204.

Berry, D. P., J. W. Bastiaansen, R. F. Veerkamp, S. Wijga, E. Wall, B. Berglund, and M. P. Calus. 2012. Genome-wide associations for fertility traits in Holstein-Friesian dairy cows using data from experimental research herds in four European countries. Animal 6:1206-1215.

Bulman, D. C., and G. Lamming. 1978. Milk progesterone levels in relation to conception, repeat breeding and factors influencing acyclicity in dairy cows. J. Reprod. Fertil. 54:447-458.

Campos, M. S., C. J. Wilcox, C. M. Becerril, and A. Diz. 1994. Genetic parameters for yield and reproductive traits of Holstein and Jersey cattle in Florida. J. Dairy Sci. 77:867-873.

Darwash, A. O., G. E. Lamming, and J. A. Woolliams. 1997a. Estimation of genetic variation in the interval from calving to postpartum ovulation of dairy cows. J. Dairy Sci. 80:1227-1234.

Darwash, A. O., G. E. Lamming, and J. A. Woolliams. 1997b. The phenotypic association between the interval to post-partum ovulation and traditional measures of fertility in dairy cattle. Anim. Sci. 65:9-16.

Darwash, A. O., G. E. Lamming, and J. A. Woolliams. 1999. The potential for identifying heritable endocrine parameters associated with fertility in post-partum dairy cows . Anim. Sci. 68:334.

Etherington, W. G., K. A. Christie, J. S. Walton, K. E. Leslie, S. Wickstrom, and W. H. Johnson. 1991. Progesterone profiles in postpartum Holstein dairy cows as an aid in the study of retained 
fetal membranes, pyometra and anestrus. Theriogenology 35:731746.

Friggens, N. C., M. Bjerring, C. Ridder, S. Højsgaard, and T. Larsen. 2008. Improved detection of reproductive status in dairy cows using milk progesterone measurements. Reprod. Domest. Anim. 43:113-121.

Gilmour, A. R., B. R. Cullis, and R. Thompson. 2009. ASReml Update: What's new in Release 3.00 VSN International Ltd., Hemel Hempstead, UK.

Hayes, J. F., R. I. Cue, and H. G. Monardes. 1992. Estimates of repeatability of reproductive measures in Canadian Holsteins. J. Dairy Sci. 75:1701-1706.

Jansen, J. 1985. Genetic aspects of fertility in dairy cattle based on analysis of A.I. data-A review with emphasis on areas for further research. Livest. Prod. Sci. 12:1-12.

Lamming, G. E., and A. O. Darwash. 1998. The use of milk progesterone profiles to characterise components of subfertility in milked dairy cows. Anim. Reprod. Sci. 52:175-190.

Lucy, M. C. 2001. Reproductive loss in high-producing dairy cattle: Where will it end? J. Dairy Sci. 84:1277-1293.

Marti, C. F., and D. A. Funk. 1994. Relationship between production and days open at different levels of herd production. J. Dairy Sci. 77:1682-1690.

Nyman, S., K. Johansson, D. J. de Koning, D. P. Berry, R. F. Veerkamp, E. Wall, and B. Berglund. 2014. Genetic analysis of atypical progesterone profiles in Holstein-Friesian cows from experimental research herds. J. Dairy Sci. 97:7230-7239.

Petersson, K.-J., K. Johansson, D. J. de Koning, D. P. Berry, R. F. Veerkamp, E. Wall, and B. Berglund. 2007. Genetic analysis of postpartum measures of luteal activity in dairy cows. J. Dairy Sci. 90:427-434.

Petersson, K. J., E. Strandberg, H. Gustafsson, and B. Berglund. 2006. Environmental effects on progesterone profile measures of dairy cow fertility. Anim. Reprod. Sci. 91:201-214.

Pollott, G. E., and M. Coffey. 2008. The effect of genetic merit and production system on dairy cow fertility, measured using progesterone profiles and on-farm recording. J. Dairy Sci. 91:3649-3660.

Pryce, J., R. J. Esslemont, R. Thompson, R. F. Veerkamp, M. A. Kossaibati, and G. Simm. 1998. Estimation of genetic parameters using health, fertility and production data from a management recording system for dairy cattle. Anim. Sci. 66:577-584.

Pryce, J., R. Veerkamp, R. Thompson, W. Hill, and G. Simm. 1997. Genetic aspects of common health disorders and measures of fertility in Holstein Friesian dairy cattle. Anim. Sci. 65:353-360.

R Core Team. 2013. R: A Language and Environment for Statistical Computing. R Foundation for Statistical Computing, Vienna, Austria.

Royal, M. D., A. O. Darwash, A. P. E. Flint, R. Webb, J. Woolliams, and G. E. Lamming. 2000. Declining fertility in dairy cattle: Changes in traditional and endocrine parameters of fertility. Anim. Sci. 70:487-501.

Royal, M. D., A. P. F. Flint, and J. A. Woolliams. 2002a. Genetic and phenotypic relationships among endocrine and traditional fertility traits and production traits in Holstein-Friesian dairy cows. J. Dairy Sci. 85:958-967.

Royal, M. D., J. E. Pryce, J. A. Woolliams, and A. P. F. Flint. 2002b. The Genetic Relationship between Commencement of Luteal Activity and Calving Interval, Body Condition Score, Production, and Linear Type Traits in Holstein-Friesian Dairy Cattle. J. Dairy Sci. 85:3071-3080.

van der Lende, T., L. M. Kaal, R. M. Roelofs, R. F. Veerkamp, C. Schrooten, and H. Bovenhuis. 2004. Infrequent milk progesterone measurements in daughters enable bull selection for cow fertility. J. Dairy Sci. 87:3953-3957.

Veerkamp, R., J. Oldenbroek, and T. Van der Lende. 1998. The use of milk progesterone measurements for genetic improvement of fertility traits in dairy cattle. Pages $62-67$ in Proceedings of the International Workshop on Genetic Improvement of Functional Traits in Cattle; Fertility and Reproduction, Grub, Germany. Interbull Bull. 18, Interbull, Uppsala, Sweden.

Veerkamp, R. F., J. K. Oldenbroek, H. J. Van Der Gaast, and J. H. J. V. D. Werf. 2000. Genetic correlation between days until start of luteal activity and milk yield, energy balance, and live weights. J. Dairy Sci. 83:577-583.

Wall, E., S. Brotherstone, J. Woolliams, G. Banos, and M. Coffey. 2003. Genetic evaluation of fertility using direct and correlated traits. J. Dairy Sci. 86:4093-4102. 